\section{ОСОБЕННОСТИ РЕГУЛИРОВАНИЯ ФОРС-МАЖОРА В МЕЖДУНАРОДНОМ ЧАСТНОМ ПРАВЕ В «КОВИДНУЮ» ЭПОХУ}

\begin{abstract}
Аннотация. В работе проводится анализ регулирования отношений по освобождению от исполнения трансграничных обязательств по причине наступления форс-мажорных обстоятельств, а именно распространения новой коронавирусной инфрекции (COVID-19).

Затрагиваются вопросы практических сложностей получения в торговых промышленных палатах РФ сертификатов о наличии обстоятельств фоорс-мажора, а также проблемы использования сертификатов для доказывания данных обстоятельств в судебной практике. На международном публичном уровне было проанализировано интересное решение, которое было вынесено во Франции Апелляционным судом г. Кольмара.

В сфрере международного частного права исследованы следующие международные акты: Венская конвенция о договорах международной купли-продажи товаров 1980 г., Принципы международных коммерческих контрактов УНИДРУА в ред. 2016 г., Новые типовые оговорки МТП 2020 г. В статье раскрывается необходимость обязательного использования фрорс-мажорной оговорки в трансграничном коммерческом контракте.

Анализируется новый документ «Пояснение к Принципам международных коммерческих контрактов УНИДРУА и кризису в области здравоохранения, вызванном COVID-19» 2020 г., в котором рассматривается вопрос воздействия пандемии COVID-19 на выполнение и неисполнение международных коммерческих контрактов.
\end{abstract}

Ключевые слова: фрорс-мажор, форс-мажорная оговорка, Венская конвенция о договорах международной купли-продажи товаров 1980 г., Типовая оговорка МТП о форс-мажоре и существенном изменении обстоятельств 2020 е., Принципы УНИДРУА в ред. 2016 г., COVID-19, трансграничный коммерческий контракт.

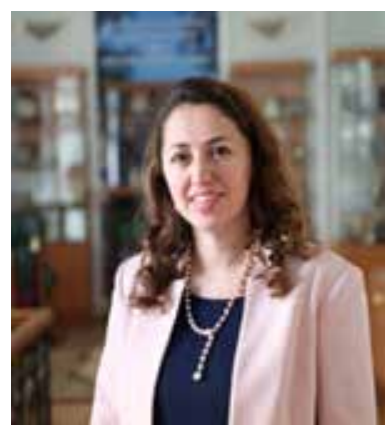

\section{Яна Олеговна АЛИМОВА,} доцент кафедры международного частного права,

заведующий кафредрой правового моделирования Университета имени О.Е. Кутафина (МГЮА), кандидат юридических наук legal-solicitor@yandex.ru 125993, Россия, г. Москва, ул. Садовая-Кудринская, д. 9

DOI: $10.17803 / 2311-5998.2021 .79 .3 .119-128$ 
Ya. O. ALIMOVA, Associate Professor of the International Private Law Department, Chief of Legal Moot Department of the Kutafin Moscow State Law University (MSAL), Cand. Sci. (Law)

legal-solicitor@yandex.ru 125993, Russia, Moscow, ul. Sadovaya-Kudrinskaya, 9

\title{
FEATURES REGULATION OF FORCE MAJEURE IN PRIVATE INTERNATIONAL LAWIN THE COVID ERA
}

\begin{abstract}
This article analyzes the regulation of relations to release from the fulfillment of cross - border obligations due to the onset of force majeure, namely the new coronavirus infection (COVID-19).

The issue of practical difficulties in obtaining certificates of force majeure circumstances in the Chamber of Commerce and Industry of Russia is discussed, and problems of using certificates to prove these circumstances in judicial practice.

At the international public level, an interesting decision was analyzed, which was rendered in France by the Colmar Court of Appeal.

In the field of private international law, the following international acts were analyzed: Vienna Convention on Contracts for the International Sale of Goods 1980, Principles of International Commercial Contracts UNIDROIT, rev. 2016, New ICC Model Clauses 2020. This article reveals the need for the mandatory use of a force majeure clause in a cross-border commercial contract. This article analyzes a new 2020 documents «Note on the UNIDROIT Principles of International Commercial Contracts and the COVID-19 health crisis», whichexplained the impact of the COVID-19 pandemic on the performance and non-performance of international commercial contracts.

Keywords: force majeure, force majeure clause, 1980 Vienna Convention on Contracts for the International Sale of Goods, ICC Model Clause of Force Majeure and Substantial Change of Circumstances 2020, UNIDROIT Principles as amended by Feb 2016, COVID-19, cross-border commercial contract.
\end{abstract}

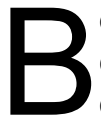

есь коммерческий мир после начала пандемии в Китае озаботился вопросом приостановления исполнения обязательств по причине наступления форс-мажорных обстоятельств, а именно COVID-19.

11 марта 2020 г. Всемирная организация здравоохранения (далее - BО3) объявила COVID-19 пандемией. По состоянию на 16 марта 2020 г. было зарегистрировано почти 165 тысяч подтвержденных случаев заболевания COVID-19 и порядка 6 тысяч смертей в 146 странах. Вспышка была объявлена чрезвычайной ситуацией в области здравоохранения. Далее последовала цепочка событий, которые существенно повлияли на трансграничные коммерческие отношения.

Стремясь защитить китайские компании от исполнения своих обязательств перед внешними контрагентами, Китайский совет по содействию международной 
торговле China Council for the Promotion of International Trade (далеe - CCPIT) объявил о выдаче китайским компаниям специальных сертификатов, подтверждающих наличие форс-мажорных обстоятельств. По состоянию на 11 марта 2020 г. ССРІТ и ее местные филиалы выдали 5637 сертификатов о форс-мажорных обстоятельствах внутренним компаниям, пострадавшим от вспышки COVID-19. Стоимость таких контрактов составляет примерно 73,2 млрд долларов США ${ }^{1}$.

В других странах, например во Франции, Индии, Испании, торговые промышленные палаты также стали выдавать сертификаты о наличии фрорс-мажорных обстоятельств в соответствии со своим внутренним законодательством огромному числу местных экспортеров. Основная цель данных сертификатов - освободить контрагентов от выполнения договорных соглашений с зарубежными партнерами.

В России свидетельствование об обстоятельствах непреодолимой силы отнесено к исключительной компетенции Торгово-промышленной палаты России².

По словам президента Торгово-промышленной палаты РФ С. Н. Катырина, «на конец апреля в ТПП РФ с подобными заявлениями обратились более 540 компаний. Только 130 из них получили сертификаты о форс-мажоре, а для 330 компаний были подготовлены и представлены ответы, поскольку у многих из заявителей не хватало документов, а у кого-то из них не было оснований для выдачи сертификата» ${ }^{3}$.

К региональным палатам ТПП в РФ было зафиксировано более 11,5 тысяч обращений по фрорс-мажорам ${ }^{4}$. Так, по состоянию на 21 сентября 2020 г. в Московскую ТПП поступило 3294 заявления о наступлении форс-мажорных обстоятельств по внутрироссийским договорам. Однако более 70 \% заявлений вернулись обратно, поскольку обстоятельства, на которые ссылались предприниматели, не относились к форс-мажорным либо не содержали обязательных документов и пояснений 5 .

Перечислим следующие основания, которые могут являться причинами отказа в получении сертификата в ТПП России: отсутствие документов, необходимых для выдачи заключения об обстоятельствах форс-мажора, представление пакета

1 Anton A., Ware Jeffrey, Yang Yingxi Fu-Tomlinson, Timothy C. Smyth. What to Do When You Receive a Coronavirus-Related Force Majeure Notice // URL: https://www.arnoldporter.com/ en/perspectives/publications/2020/03/what-to-do-when-you-receive-a-coronavirus (дата обращения: 26.10.2020).

2 В соответствии с пп. «н» п. 3 ст. 15 Закона РФ от 7 июля 1993 г. № 5340-1 «О торговопромышленных палатах в Российской Федерации» и п. 2.1 Положения о порядке свидетельствования ТПП России обстоятельств непреодолимой силы (форс-мажора), утвержденного постановлением правления ТПП России от 23 декабря 2015 г. № 173-14.

3 Панина Т. Интервью с президентом Торгово-промышленной палаты РФ. Сергей Катырин назвал регионы, где у бизнеса больше всего форс-мажора // Российская газета. 27 апреля 2020 г. URL : https://tpprf.ru/ru/news/sergey-katyrin-nazval-regiony-gde-u-biznesa-bolshevsego-fors-mazhora-i358199/ (дата обращения: 26.10.2020).

4 Панина T. Указ. соч.

5 Офиициальный сайт Московской ТTП РФ. URL: https://mostpp.ru/news/fors-mazhor/forsmazhor-iz-za-koronavirusa-voprosy-i-otvety (дата обращения: 25.10.2020). 
документов ненадлежащим заявителем, отсутствие в контракте форс-мажорной оговорки или неверное ее составление и др.

Следует помнить, что трансграничный коммерческий контракт обязательно должен содержать правильно составленную фрорс-мажорную оговорку. В контракт следует включить отдельное положение, посвященное форс-мажору, где среди фрорс-мажорных обстоятельств должны указываться, например, эпидемия или пандемия. В таком случае контрагент сможет получить сертификат от ТПП и сослаться на эти условия договора в суде. Если же контракт не содержит фрорс-мажорную оговорку, то будет применяться общее правило. По нему к форсмажору относятся чрезвычайные и непредотвратимые объективные обстоятельства, которые стали причиной неисполнения обязательств по договору. Этих обстоятельств невозможно было избежать, и существовала прямая связь между наступлением пандемии и неисполнением условий договора. Если договор был заключен уже в период пандемии, то контрагент, скорее всего, не сможет ссылаться на форс-мажор.

Надлежащим заявителем по обращению в ТПП РФ будет являться только сторона трансграничной коммерческой сделки, не исполнившая или ненадлежащим образом исполнившая контрактные обязательства.

ТПП России может засвидетельствовать только те события, связанные с массовым заболеванием, или те специальные меры государственных органов, направленные на предупреждение его распространения, которые имели место на территории Российской Федерации и находятся в причинно-следственной связи с исполнением внешнеторговой сделки ${ }^{6}$.

На практике возникает вопрос о том, насколько наличие данного сертификата, который был выдан ТПП РФ или ССРІТ Китая, может гарантировать, что сторона будет освобождена от исполнения обязательств по контракту? Этот вопрос особенно важен, если дело будет в итоге рассматриваться в английском или американском суде.

Получив сертификат и уведомление от своего контрагента о том, что он не может выполнить свои обязательства по контракту из-за вспышки COVID-19, необходимо выполнить следующие действия. Во-первых, проверить, содержит ли ваш контракт фрорс-мажорную оговорку. Во-вторых, определить право, применимое к контракту. Следует помнить, что сторона будет освобождена от ответственности, только если докажет наличие форс-мажорных обстоятельств согласно применимому праву.

Далее необходимо проанализировать текст фрорс-мажорной оговорки и удостовериться, что заявленное событие действительно можно квалифицировать как фрорс-мажорное, а также установить причинно-следственную связь между форс-мажорным событием и неисполнением контракта и др.

Хотелось бы отметить, что первые два действия являются самыми важными, поскольку в случае, если в вашем контракте отсутствует такая оговорка, то, как отмечается многими специалистами, вашему контрагенту останется только рассмотреть вопрос о том, что неисполнение может быть оправдано английской доктриной «тщетностью исполнения» либо американской доктриной

6 Официальный сайт Московской ТТП. 


\begin{tabular}{|c|c|}
\hline 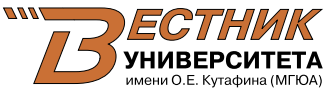 & $\begin{array}{l}\text { Алимова я. } \boldsymbol{~} \text {. } \\
\text { Фсобенности регулирования форс-мажора } \\
\text { в международном частном праве в «ковидную» эпоху }\end{array}$ \\
\hline
\end{tabular}

«неосуществимостью исполнения» ${ }^{7}$. В любом случае, только английский или американский суд окончательно решит вопрос о наличии или отсутствии форсмажорного обстоятельства. Сторона, заявляющая о форс-мажоре, обязательно должна предоставить все доказательства наличия обстоятельств, которые предположительно препятствуют исполнению контракта.

Все эти примеры свидетельствуют о том, что следует еще раз обратиться к тем подходам, которые сложились на международном и национальном уровнях регулирования.

В международном праве под форс-мажорным обстоятельством понимается такая ситуация, при которой субъект вынужден действовать вопреки международному обязательству в результате действия непреодолимой силы или не поддающегося контролю непредвиденного события ${ }^{8}$

C самого начала распространения COVID-19 важный вопрос касается споров инвесторов с государствами, которые не предприняли соответствующих мер по уменьшению распространения коронавирусной инфекции либо предприняли действия, нарушающие стандарты обращения с инвесторами.

В науке выделяются следующие стандарты обращения с инвесторами: справедливое и равноправное обращение; полная защита и безопасность; недопустимость экспроприации без предоставления компенсации; обязательства, вытекающие из зонтичной оговорки (umbrella clause); национальный режим; режим наибольшего благоприятствования 9

Некоторые меры, принятые государствами в ответ на COVID-19, могут быть оспорены в инвестиционном арбитраже, как, например, действия властей Индии по ограничению экспорта 26 активных фармацевтических ингредиентов, которые составляют около 10 \% экспорта; действия властей Испании, которые уполномочили министра здравоохранения «вмешиваться и временно занимать предприятия, фабрики, мастерские, фермы или помещения любого характера, включая частные медицинские центры, службы и учреждения, а также те учреждения, которые осуществляют свою деятельность в фармацевтическом секторе, чтобы государство могло обеспечить поставку товаров и услуг, необходимых для охраны здоровья населения» ${ }^{10}$.

Государство со ссылкой на ст. 23 Резолюции ООН должно доказать, что обстоятельства, вынудившие его нарушить международные обязательства, не обусловлены поведением самого государства и не могли быть им предвидены.

На основе анализа практики разрешения арбитражных споров между инвестором и государством большинство экспертов полагают, что суды склонны

7 Подробнее об этом см.: Anton A., Ware Jeffrey, Yang Yingxi Fu-Tomlinson, Timothy C. Smyth. Op. cit.

8 Подробнее см.: Лукашук И. И. Международное право. Особенная часть : учебник. 2-е изд., перераб. и доп. М. : Бек, 2001. 320 с.

9 COVID-19 и международное право : обзор публикаций / Центр международных и сравнительно правовых исследований. М., 2020. Вып. 4. П. 42. URL: https://iclrc.ru (дата обращения: 25.12.2020).

${ }^{10}$ Hailes $\mathrm{O}$. Epidemic Sovereignty? Contesting investment treaty claims arising from coronavirus measures // URL: https://www.ejiltalk.org/epidemic-sovereignty-contesting-investment-treatyclaims-arising-from-coronavirus-measures/ (дата обращения: 25.12.2020). 
отвергать ссылку на форс-мажорные обстоятельства в оправдание принятых мер ${ }^{11}$.

Ниже хотелось бы привести решение национального суда, которое может быть и по иному спору, но уже признало COVID-19 фрорс-мажорным обстоятельством. Такое интересное решение было вынесено во Франции по международным публичным отношениям.

Как отмечает французский профессор П. Л. Грюнбаум, «для того, чтобы французский суд квалифицировал ситуацию как форс-мажор, данная ситуация всегда должна одновременно обладать тремя характеристиками: быть “внешней”, “непредсказуемой" и “непреодолимой” ${ }^{12}$.

Когда-то считалось, что для характеристики форс-мажора нужен только критерий непреодолимости. Однако Пленум Кассационного суда подтвердил свое решение от 14 апреля 2006 г. (апелляционная жалоба № 04-18.902), что для признания события фрорс-мажорным должны быть созданы все три условия, а именно оно должно быть непредсказуемым, непреодолимым и внешним ${ }^{13}$.

В приведенном ниже деле Апелляционный суд г. Кольмара установил все три критерия и признал COVID-19 обстоятельством непреодолимой силы по делу о передаче гражданина Сенегала, нелегально находившегося на территории Франции, испанским властям ${ }^{14}$.

12 марта 2020 г. Апелляционный суд г. Кольмара, вынес судебное решение, в котором признал, что для признания ситуации форс-мажорной она должна иметь следующие обязательные характеристики: быть «внешней», «непредсказуемой» и «непреодолимой».

В отношении непреодолимости события суд указал, что участие задержанного в слушании не могло быть обеспечено ни посредством организации видеоконференц-связи, ни путем сопровождения его на слушание. Следовательно, не

${ }_{11}$ COVID-19 и международное право : обзор публикаций. Вып. 4.

${ }^{12}$ Grynbaum P. L. Force majeure et épidémie de COVID -19: une première décision vient d'être rendue // URL: https://www.leclubdesjuristes com/blog-du-coronavirus/que-dit-le-droit/forcemajeure-et-epidemie-de-covid-19-les-premieres-decisions-viennent-detre-rendues/ (дата обращения: 07.11.2020).

13 Grynbaum P. L. Op. cit.

${ }^{14} 5$ августа 2019 г. префрект департамента Нижнего Рейна подписал приказ о передаче гражданина Сенегала, нелегально находившегося на территории Франции, испанским властям, приняв во внимание, что заявление о предоставлении статуса беженца было подано именно в Испании, а также посадил беженца под домашний арест. Однако гражданин Сенегала не соблюдал предписания префекта и упорно отказывался подняться на борт самолета, летящего в Испанию. В результате 12 февраля 2020 г. он был помещен французскими властями под временный арест в центр содержания под стражей (административное задержание) сроком на 28 дней. 10 марта префектура запросила продление задержания на 30 дней. В заседании 11 марта судья по вопросам свободы и заключения суда г. Страсбурга удовлетворил этот запрос. В тот же день задержанный подал на апелляцию. Апелляционный суд г. Кольмара, на заседание которого задержанный не смог явиться, но на котором интересы задержанного представлял его адвокат, подтвердил решение суда первой инстанции (Жукова Г. Пандемия COVID-19 и форс-мажорные обстоятельства: первое решение фрранцузских судов // Arbitration.ru. April, 2020. № 3 (18). C. 77-78. 


\begin{tabular}{|c|c|}
\hline 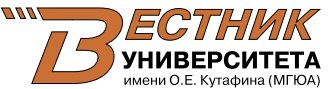 & $\begin{array}{l}\text { Алимова я. } \boldsymbol{~} \text {. } \\
\text { Фсобенности регулирования форс-мажора } \\
\text { в международном частном праве в «ковидную» эпоху }\end{array}$ \\
\hline
\end{tabular}

существовало никакой возможности предотвратить неявку гражданина Сенегала на слушание.

Таким образом, это первое дело, в котором суд, пусть и не по экономическим спорам, признал COVID-19 обстоятельством непреодолимой силы.

По трансграничным коммерческим отношениям пандемия COVID-19 может быть оценена как форс-мажорное обстоятельство, исключающее ответственность должника, только в тех ситуациях, когда исполнение обязательств совсем не представляется возможным.

Первый важный международный акт, в котором поднимается вопрос освобождения контрагентов от исполнения обязательств, - Венская конвенция о договорах международной купли-продажи товаров 1980 г. (далее - Венская конвенция).

Так, статья 79 Венской конвенции гласит, что «сторона не несет ответственности за неисполнение любого из своих обязательств, если докажет, что оно было вызвано препятствием вне ее контроля и что от нее нельзя было разумно ожидать принятия этого препятствия в расчет при заключении договора либо избежания или преодоления этого препятствия или его последствий» ${ }^{15}$. При этом факт невозможности исполнения обязательства должником не принимается во внимание, если исполнение объективно было возможно.

Обращает на себя внимание то, что, желая придать Венской конвенции достаточную гибкость, ее разработчики использовали абстрактные категории, в частности, вместо понятия «форс-мажор», «непреодолимая сила» вводится категория «препятствие», вместо слова «вина» - выражение «вне контроля».

Также за разъяснением о том, при каких обстоятельствах сторона освобождается от ответственности за неисполнение контракта, можно обратиться к документу рекомендательного характера под названием Принципы международных коммерческих договоров УНИДРУА в ред. 2016 г. (далее - Принципы УНИДРУА).

Согласно ст. 7.1.7 Принципов УНИДРУА сторона освобождается от ответственности за неисполнение, если докажет, что неисполнение было вызвано препятствием вне ее контроля и что от нее нельзя было разумно ожидать принятия этого препятствия в расчет при заключении договора либо избежания или преодоления этого препятствия или его последствий. Таким образом, под форс-мажорными понимаются обстоятельства, соответствующие следующим критериям:

- обстоятельство препятствует исполнению обязательства;

- обстоятельство находится вне контроля не исполнившей обязательство стороны;

- на момент заключения договора стороны не могли предполагать наступления таких обстоятельств.

В целом положения ст. 7.1.7 Принципов УНИДРУА о форс-мажоре совпадают С п. 3 ст. 4.1 ГК РФ. Особое значение следует придать п. 4 ст. 7.1.7 Принципов УНИДРУА, согласно которому «положения настоящей статьи не препятствуют стороне воспользоваться правом прекратить договор или приостановить исполнение либо требовать уплаты процентов годовых» ${ }^{16}$.

15 Конвенция Организации Объединенных Наций о договорах международной купли-продажи товаров (Вена, 1980 г.) (КМКПТ) // URL: https://uncitral.un.org/en/texts/salegoods/ conventions/sale_of_goods/cisg (дата обращения: 25.12.2020).

16 Принципы международных коммерческих договоров УНИДРУA // URL: https://www.unidroit. 
Причем на обязанность платить проценты даже в том случае, когда нарушитель освобождается от ответственности, специально указывает еще и п. 1 ст. 7.4.9 Принципов. Все это расходится с тем подходом, который заложен в законодательстве РФ. Как справедливо отмечает В. А. Белов, «поскольку проценты по ст. 395 нашего ГК, хотя и объясняются с экономической точки зрения как плата за пользование фактически оказанным кредитом, но с юридической точки зрения продолжают считаться мерой гражданско-правовой ответственности, а коль скоро форс-мажор освобождает от таковой, то и проценты по ст. 395 ГК РФ за нарушение, вызванное фоорс-мажором, нарушитель платить не обязан. Как видим, получается вывод, прямо противоположный предписанию Принципов УНИДРУА» ${ }^{17}$.

Особый интерес представляет также ст. 6.2.2 «Определение затруднений», а также ст. 6.2.3 «Последствия затруднений» Принципов УНИДРУА 2016 г.

Отдельно хотелось бы отметить, что в 2019 г. Секретариат УНИДРУА выпустил Пояснение к Принципам международных коммерческих контрактов УНИДРУА и кризису в области здравоохранения, вызванному COVID-1918.

В этом документе отмечается, что он не носит завершающего характера и может быть дополнен новыми положениями. Документ разделен на четыре части. Первая касается общих вопросов: сферы и содержания документа, описания временны́х этапов распространения коронавирусной инфекции в разных странах, механизма работы с данным документом. Вторая часть полностью посвящена толкованию ст. 7.1.7, третья часть - ст. 6.2 .2 и 6.2.3, а четвертая - соотношению положений о форс-мажоре и Hardship.

По вопросу применения ст. 7.1.7 Принципов УНИДРУА к отношениям, возникающим в связи с COVID-19, комментаторы указывают о важности обязательного установления причинно-следственной связи между событием (пандемией) и неисполнением контракта. В данном документе определяется, что пандемия могла оказать разное влияние на контракты:

- прямое влияние, когда затронуто здоровье ключевого исполнителя. Это касается таких контрактов, в которых личность исполнителя важна и имеет решающее значение при исполнении контракта;

- косвенное влияние, через временную приостановку или ограничение определенных видов деятельности путем введения государственными органами специальных мер, например, приостановление работы заводов, ограничение перемещений сотрудников, которые вели деятельности за границей, создание препятствий, влияющих на деятельность деловых партнеров в других странах (невозможность импорта товаров от поставщиков из-за запрета экспорта).

Однако есть ряд контактов, на которые COVID-19 не оказал ни прямого, ни косвенного влияния. Например, контракты, заключаемые в сфере электронной коммерции, стали пользоваться большой популярностью во время пандемии.

org/instruments/commercial-contracts/unidroit-principles-2016 (дата обращения: 25.12.2020).

17 Белов В. А. Международное торговое право и право ВТО : учебник для бакалавриата и магистратуры : в 2 т. М. : Юрайт, 2014. Т. 2 : Акты международной частноправовой унификации. Право ЕС. Право ВТО. С. 58.

${ }^{18}$ Note on the UNIDROIT Principles of International Commercial Contracts and the COVID-19 health crisis // URL: https://www.unidroit.org/english/news/2020/200721-principlescovid19-note/note-e.pdf (дата обращения: 25.12.2020). 
Относительно толкований ст. 1.7 комментаторы приходят к выводу, что большое значение играют место и время заключения контракта. На международном уровне для определения предвидимости наступления коронавирусной инфекции и ее последствий важность имеют следующие периоды заключения контракта: конец декабря 2019 г. (объявление китайскими властями о заболевании); после 30 января 2020 г. (ВО3 объявила COVID-19 чрезвычайной ситуацией); после 11 марта 2020 г. (ВОЗ объявила COVID-19 пандемией).

Также значение придается моменту заключения контракта в конкретной юрисдикции. Считается, что, пока пандемия не достигла стран, в которых стороны имеют свои коммерческие предприятия, новость об опасности данной инфекции, имеющей место за границей, в некоторых случаях может означать лишь будущую вероятность распространения инфекции в этих странах. Считается, что чем ближе находятся коммерческие предприятия сторон к стране, в которой COVID-19 получил широкое распространение, тем разумнее ожидать, что коммерсанты предвидели пандемию и ее последствия для исполнения контракта. Однако наличия одного только критерия - «географическая удаленность» стран контрагентов, заключающих контракт, может быть недостаточно для исключения предсказуемости ${ }^{19}$.

Эти и иные вопросы были подробно изложены в рассматриваемом документе, и все они демонстрируют те практические сложности, которые могут возникнуть при квалификации COVID-19 в качестве форс-мажорного обстоятельства.

Еще одним нововведением является то, что Международная торговая палата (далее - МТП) в 2020 г. обновила Оговорки о фоорс-мажоре и существенном изменении обстоятельств, в которых также даются важные рекомендательные разъяснения по поводу применения форс-мажора.

Новая оговорка о форс-мажоре МТП теперь содержит 28 новых изменений по сравнению с 2003 г.

Перечислим некоторые из них: 1) из категории военных действий исключаются блокада и военное эмбарго, беспорядки, а также угроза вооруженного конфрликта. Военная мобилизация теперь должна быть обширной, чтобы попасть под оговорку; 2) в категории социальных потрясений мятеж и акты неповиновения заменены на бунт, восстание и революцию. В эту же категорию отнесены теракты, саботаж и пиратство; 3) из категории государственных предписаний вынесены и выделены в отдельную валютные и торговые ограничения, эмбарго, санкции, однако был исключен комендантский час; 4) выражение Acts of God исключено из текста оговорки, в том числе из английской версии; 5) введено понятие «пандемия»; 6) техногенные катастрофы дополнены длительным выходом из строя информационной системы или энергоресурсов.

Основные нововведения оговорок - это, во-первых, разработка новой краткой формы оговорки о форс-мажоре, которая состоит из нескольких ключевых положений, охватывающих наиболее важные аспекты форс-мажора, и особенно подходит для использования компаниями среднего и малого бизнеса, а во-вторых, представление различных вариаций оговорки о существенном изменении обстоятельств, которые позволяют расторгнуть договор или изменить его условия ${ }^{20}$.

${ }^{19}$ Note on the UNIDROIT Principles of International Commercial Contracts and the COVID-19 health crisis.

${ }^{20}$ URL: http://www.iccwbo.ru/news/2020/ICC_mezhdunarodnaya-torgovaya-palata-icc-obnovilaogov/ (дата обращения: 25.12.2020). 
В заключение хотелось бы отметить, что ситуация с COVID-19 до сих пор полностью не нормализовалась. Границы ряда стран остаются закрытыми. Многие проекты, которые должны были выполняться иностранными работниками, заморожены по причине того, что люди не могу приехать в страны, в которых в настоящее время действуют режимы локдауна, например во Францию, в Великобританию и др.

Правильное формулирование форс-мажорной оговорки, проработка механизма последующих действий сторон, знание новых актов обязательного и рекомендательного характера, а также новейшей судебной практики могут иметь огромное значение и помочь контрагентам трансграничных коммерческих контрактов разрешить их спорные вопросы.

\section{БИБЛИОГРАФИЯ}

1. Белов В. А. Международное торговое право и право ВТО : учебник для бакалавриата и магистратуры : в 2 т. - М. : Юрайт, 2014. - Т. 2 : Акты международной частноправовой унификации. Право ЕС. Право ВТО. - 615 с.

2. Жукова Г. Пандемия COVID-19 и форс-мажорные обстоятельства: первое решение французских судов // Arbitration.ru. - April, 2020. — № 3 (18).

3. Лукашук И. И. Международное право. Особенная часть : учебник. - 2-е изд., перераб и доп. - М. : Бек, 2001. - 320 c.

4. Anton A., Ware Jeffrey, Yang Yingxi Fu-Tomlinson, Timothy C. Smyth. What to Do When You Receive a Coronavirus-Related Force Majeure Notice // URL: https:// www.arnoldporter.com/en/perspectives/publications/2020/03/what-to-do-whenyou-receive-a-coronavirus (дата обращения: 26.10.2020).

5. COVID-19 и международное право : обзор публикаций / Центр международных и сравнительно правовых исследований. - М., 2020. - Вып. 4. — URL: https:// iclrc.ru (дата обращения: 25.12.2020).

6. Grynbaum P. L. Force majeure et épidémie de COVID-19: une première décision vient d'être rendue // URL: https://www.leclubdesjuristes.com/blog-du-coronavirus/ que-dit-le-droit/force-majeure-et-epidemie-de-covid-19-les-premieres-decisionsviennent-detre-rendues/ (дата обращения: 25.12.2020).

7. Hailes $\mathrm{O}$. Epidemic Sovereignty? Contesting investment treaty claims arising from coronavirus measures // URL: https://www.ejiltalk.org/epidemic-sovereigntycontesting-investment-treaty-claims-arising-from-coronavirus-measures/ (дата обращения: 25.12.2020).

8. Note on the UNIDROIT Principles of International Commercial Contracts and the COVID-19 health crisis // URL: https://www.unidroit.org/english/news/2020/ 200721-principles-covid19-note/note-e.pdf (дата обращения: 25.12.2020). 